\title{
Identifying Surface Temperature Pattern of the City of Colombo
}

\section{Manawadu and Nirosha Liyanage}

Abstract: The recent climatological studies carried out by several scholars from different disciplines have proved that the surface temperature of the urban areas has been elevated over the neighbouring vegetated areas. This trend can be experienced not only in industrialized countries but also in developing countries, induced by global warming. The trend of increasing temperature has extensively been felt by every single person of all regions in the world including the coldest region; Atlantic. Therefore, scientific studies on weather anomalies have been widely taken by various scholars in different fields. However, the technical constraints to examine the air temperature in urban areas especially in developing countries are very significant. For an instance, Colombo, the largest commercial city in Sri Lanka, Colombo has only one meteorological observatory which is located near the Southeast boundary of the city. This makes some restrictions to analyze the spatial pattern of temperature and the temperature levels in core area of the city. The present study attempts to examine the spatial pattern of surface temperature using remotely sensed data and examine the factors influencing the elevation of temperature in the city of Colombo.

Key Words: Surface Temperature, Heat Islands, NDVI,

\section{Introduction}

Several studies carried out by different scholars have indicated that the world climate has got hotter during the last two decades. Similarly, there is a very significant periodic and seasonal variation in the air temperature of the city of Colombo. The average air temperature of the city for last 100 years (1901 to 2001) is $27.25^{\circ} \mathrm{c}$. However, still there are some outliers and deviations in some years from the average temperature of the city (Figure 1). Annual temperature deviations given in Figure 1 demonstrate very comprehensible periodic changes of air temperature in the city of Colombo. Deviations in the middle part of the graph are always below the average of temperature of the last 100 years (27.250c). However in the recent years most of the deviations are positive

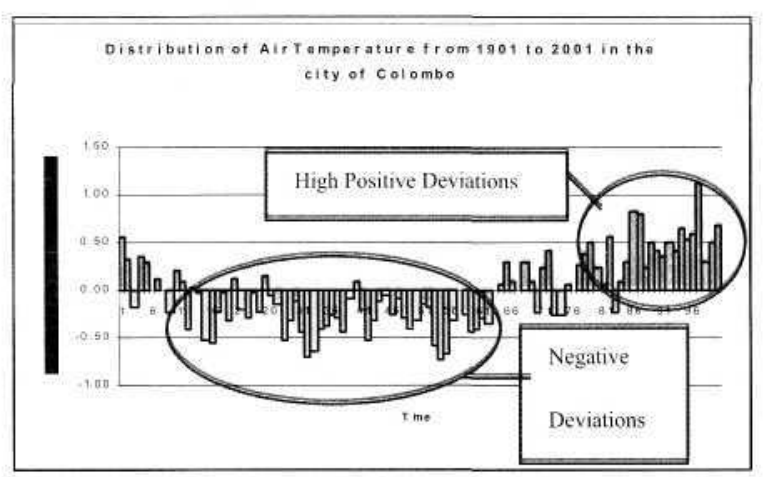

Figure 1: Distribution of Air Temperature
These characteristics indicate a trend of increasing temperature of the city in recent past. Figure 2; the trend line drawn for the entire period, clearly indicates that there is a very significant trend of increasing the air temperature in future.

\section{Objectives of the Study}

The main objective of this study is to examine the surface temperature of the city of Colombo

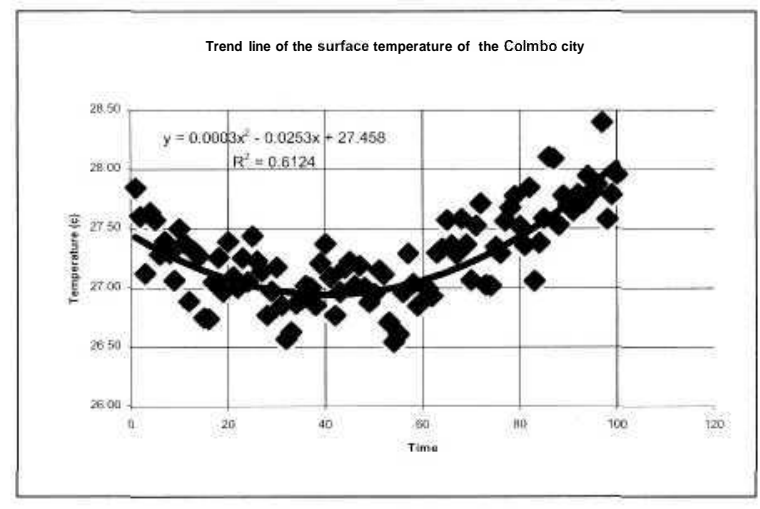

Figure: 2 Polynomial trend line of the temperature of the city of Colombo

Source: prepared by author - 2008

L. Manawadu, Senior Lecturer, Department of Geography, University of Colombo, B.A. in Geography, Department of Geography, University of Colombo, MSc in Urban Planning, Asian Institute of Technology, Bangkok, Thailand.

Ms. Nirosha Liyanage, Lecturer, Department of Geography, University of Colombo, B.A. (Honors) Geography, 2006, Department of Geography, University of Colombo. 
in different analytical views. The specific objectives are;

a. Extraction of surface temperature using remotely sensed data

b. Examination of spatial pattern of the surface temperature

c. Examination of factors influencing the elevation of surface temperature in the city of Colombo

The city of Colombo was chosen as the target area for this study. The high rate of urbanization, concentration of secondary and tertiary economic activities, large number of vehicle population and fuel consumption, artificial surfaces and low vegetation cover are some of the main characteristics of this area. Therefore, study on temperature is an indirect attempt to examine the level of heat trapping gases in the city of Colombo.

\section{Literature Review}

High rate of urbanization has resulted in drastic demographic, economic, land usage and land coverage and climatic changes in all parts of the world. The growth and expansion of cities entail the construction of new roads, buildings, and other man-made structures to accommodate the growing population and in turn, the destruction of the natural ground cover and landscape. As a result, urban micro-climates, referred to as urban heat islands with increased temperatures of $2.8^{\circ} \mathrm{f}$ or sometimes more than that with high concentration of pollutants are created. Temperature is one of the indicators that determine the quality of air. Even though, air temperature and surface temperature are two different phenomenon and concepts, there is a very significant positive relationship between these two physical characteristics. A prior understanding of air temperature will help to understand surface temperature in any area.

At present, the concept of urban surface temperature and the urban 'heat islands' are the most prominent topics in climatology. As a developing country, though the attention to urban climatic phenomenon has been drawn very recently, some authors from developed world have made significant effort to study the urban phenomenon since 19th century. David Streutker explains some basic characteristics of urban heat islands and it is a milepost of several studies on urban heat islands.

'One of the most well known forms of anthropogenic climate modifications is the phenomenon of urban heating. Modification of land cover in urban areas can cause the local air and surface temperature to rise several degrees higher than the simultaneous temperatures of surrounding rural areas. This effect is often referred to as the urban heat island (UHI) and has been documented for over 150 years (Howard, 1833). Over the past few years, UHIs have been studied in cities in diverse countries such as Lodz, Poland (Klysik \& Fortuniak, 1999), Reykjavik, Iceland (Steinecke, 1999), and Granada, Spain (Montavez Rodriguez \& Jimenez, 2000) (Streutker, 2003).

The report of Initial National Communication under the United Nations Framework Convention on Climate Changes had indicated that, there is a trend of increasing temperature in Sri Lanka as follows:

'Temperature, rainfall and other metrological data have been collected by the Department of Meteorology over a period of more than 100 years. Statistical analyses of the temperature data have shown an increasing trend in the annual mean air temperature over the entire island particularly during $1961-1990$. This increase was found to be approximately $0.16^{\circ} \mathrm{C}$ per decade' (http://unfccc.int/resource/docs/ natc/srinc1.pdf \#search="fuel\%20consumption $\% 20$ sri\%20lanka').

One of the very promising ways of studying urban surface temperature is airborne technology or satellite remote sensing (Streutker, 2003). Estimation of Land Surface Temperature (LST) from remotely sensed data is prominent at present. LST is a key parameter in the physics of land surface process because it is involved in the energy balance as well as in the evapo-transpiration and desertification process (Peres and Da Camara, 2004). The extensive use of land surface temperature for environmental studies and management activities of the earth's resources has made the remote sensing of LST an important academic topic during the last two decades (Sobrino, et al. 2004). One of the most important parameters in all surface-atmosphere interactions and energy fluxes between the 
ground and the atmosphere, is land surface temperature (Sobrizo, et al, 2003).

\section{Methodology, Data and Analysis}

Remotely sensed data were utilized to analyze the urban heat distribution and Agro-forestry in the study area. Landsat 7 ETM+ was the main source of data.

\subsection{The methods adopted extraction of surface temperature}

Estimation of the surface temperature using Landsat $7(\mathrm{ETM}+)$ was carried out in four stages. In the first stage, the following equation was used to convert DN's in to radiance.

\section{Equation 01}

$$
\mathrm{CV}^{\mathrm{R}}=\mathrm{G}\left(\mathrm{CV}_{\mathrm{DN}}\right)+\mathrm{B}
$$

Where:

$C V_{R}$ is the cell value as radiance, $C_{D N}$ is the cell value digital number, $\mathrm{G}$ is the gain and $\mathrm{B}$ is the bias (or offset)

This formula can be simplified as follows:

Equation 02

$$
\text { Radiance }=\text { Gain } * D N+\text { Offset }
$$

This can be expressed as:

\section{Equation 03}

$$
\begin{aligned}
& \text { Radiance }=\left(\left(\mathrm{L}_{\mathrm{MAX}}-\mathrm{L}_{\text {MIN }}\right) /\left(\mathrm{QCAL}_{\text {MAX }}-\right.\right. \\
& \left.\mathrm{QCAL}_{\text {MIN }}\right) *\left(\mathrm{QCAL}-\mathrm{QCAL}_{\text {MIN }}\right)+\mathrm{L}_{\text {MIN }}
\end{aligned}
$$

Where:

$\mathrm{L}_{\text {MAX }}$ is the spectral Radiance Range or high gain for specific band at digital numbers 0 or 1 and 255

$\mathrm{L}_{\mathrm{MIN}}$ is the spectral Radiance Range or low gain for specific band at digital numbers 0 or 1 and 255

QCAL $_{\text {MIN }}$ is the value, which can be the lowest among DNs

QCAL $_{\text {MAX }}$ is the value, which can be the highest among DNs

QCAL is the Digital Numbers
In the second stage, radiance values were transformed to Kelvin using the following equation.

Equation 04

$T=\frac{K_{2}}{\operatorname{In}\left[\frac{K_{1}}{C V_{R}}\right]+1}$

Where:

$\mathrm{T}$ is surface temperature in Kelvin

$\mathrm{CV}_{\mathrm{R}}$ is the cell value as radiance

$\mathrm{K}_{1}$ and $\mathrm{K}_{2}$ are calibration constants chosen to optimize the approximation for the band pass of the sensor.

In the third stage, conversion of Kelvin to Celsius and Celsius to Fahrenheit were done using a free software.

\subsection{The methods adopted to identify agro-forestry}

Landsat TM bands $3(0.63-0.69 \mu \mathrm{m})$ and 4 (0.76$0.90 \mu \mathrm{m}$ ) have been utilized to identify the forest cover of the study area. The NDVI (Normalized Difference Vegetation Index) is an index that provides a standardized method of comparing vegetation greenness between satellite images. NDVI is defined as the difference between the visible (red) and near-infrared bands. The NDVI is an alternative measure of vegetation amount and condition. It is associated with vegetation canopy characteristics such as biomass, leaf area index and percentage of vegetation cover. The formula to calculate NDVI is:

\section{Equation 05}

NDVI = (near IR band - red band) / (near IR band + red band)

Index values can range from -1.0 to 1.0 , but vegetation values typically range between 0.1 and 0.7. Higher index values are associated with higher levels of healthy vegetation cover; bare soil and rock reflect similar levels of nearinfrared and red and thus will have NDVI values near zero. Clouds, water, and snow are the opposite of vegetation in that they reflect more visible energy than infrared energy, and so they yield negative NDVI values. 


\section{Results and Discussion}

\subsection{Surface temperature in the city of Colombo}

The average surface temperature of the city of Colombo is $91.1298^{\circ} \mathrm{f}$ (305.9999 Kelvin) ranging from $81.23^{\circ} \mathrm{f}$ (300.5 Kelvin) (Lowest) to $99.23^{\circ} \mathrm{f}$ (310.5) (Highest). The lower value is little higher than the average air temperature $\left(91.1298^{\circ} \mathrm{f}\right)$ of the city. It indicates the surface temperature of the city is always higher than the average air temperature.

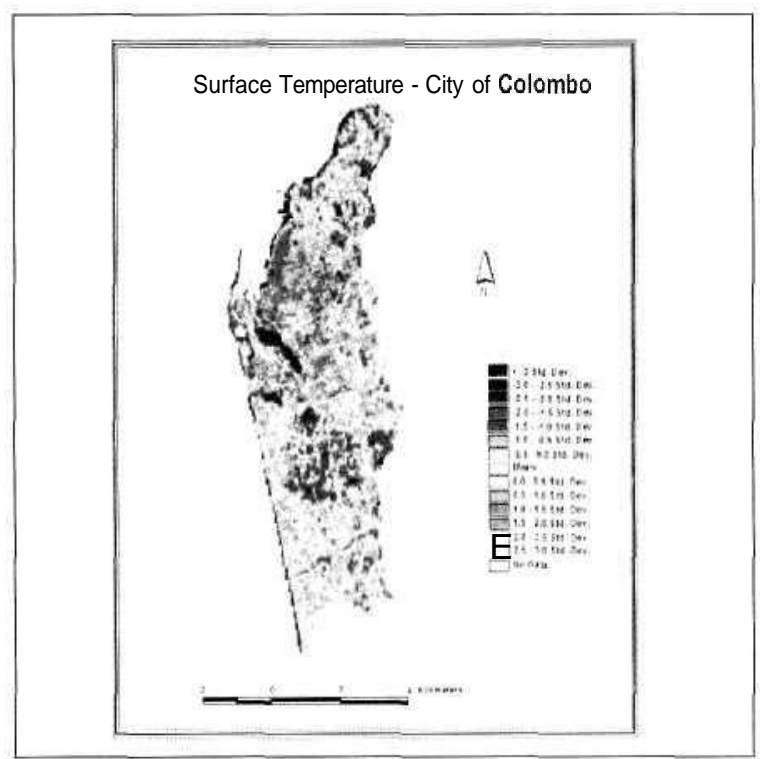

Source: prepared by the Author - 2008 Figure 3: Suface Temperature - Colombo

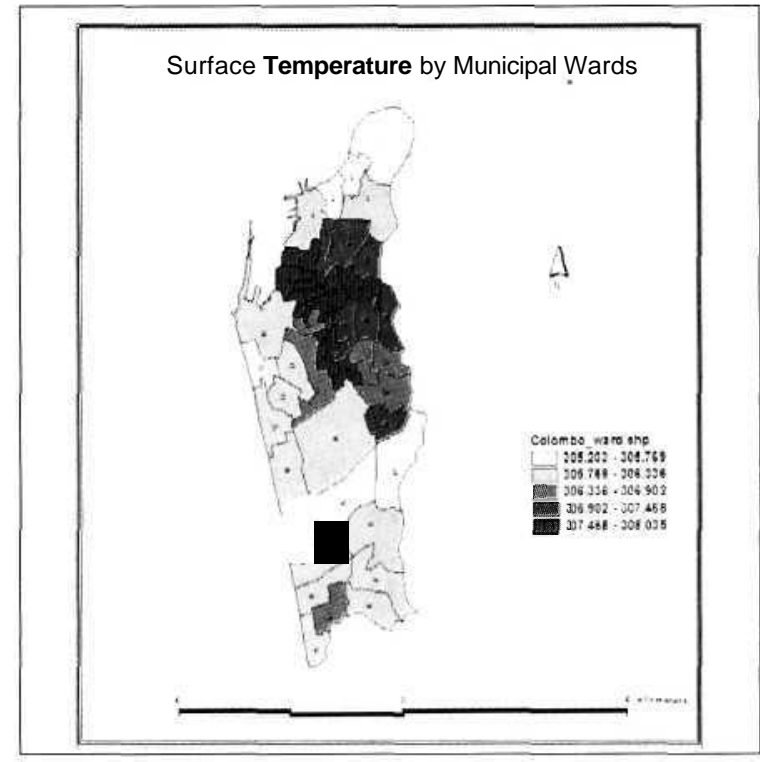

Source: prepared by the Author - 2008

Figure 4: Surface Temperature- Wards

A concentration of high surface temperature in the central part of the city (harbour area), which declines towards the Northern and Southern parts of the city is the prominent spatial pattern (Figure 3). Municipal wards located in the central part of the city such as New Bazaar (308.0345 Kelvin), Kochchikade South (307.9483 Kelvin), Kochchikade North (307.9248 Kelvin), Gintupitiya (307.8729 Kelvin), Masangas Weediya (307.7951 Kelvin) indicate relatively very high temperature whilst Aluthmawatha (305.2032 Kelvin), Mattakuliya (305.2496 Kelvin) and Thimbirigasyaya (305.3811 Kelvin) wards show relatively low temperature in the city (Figure 4).

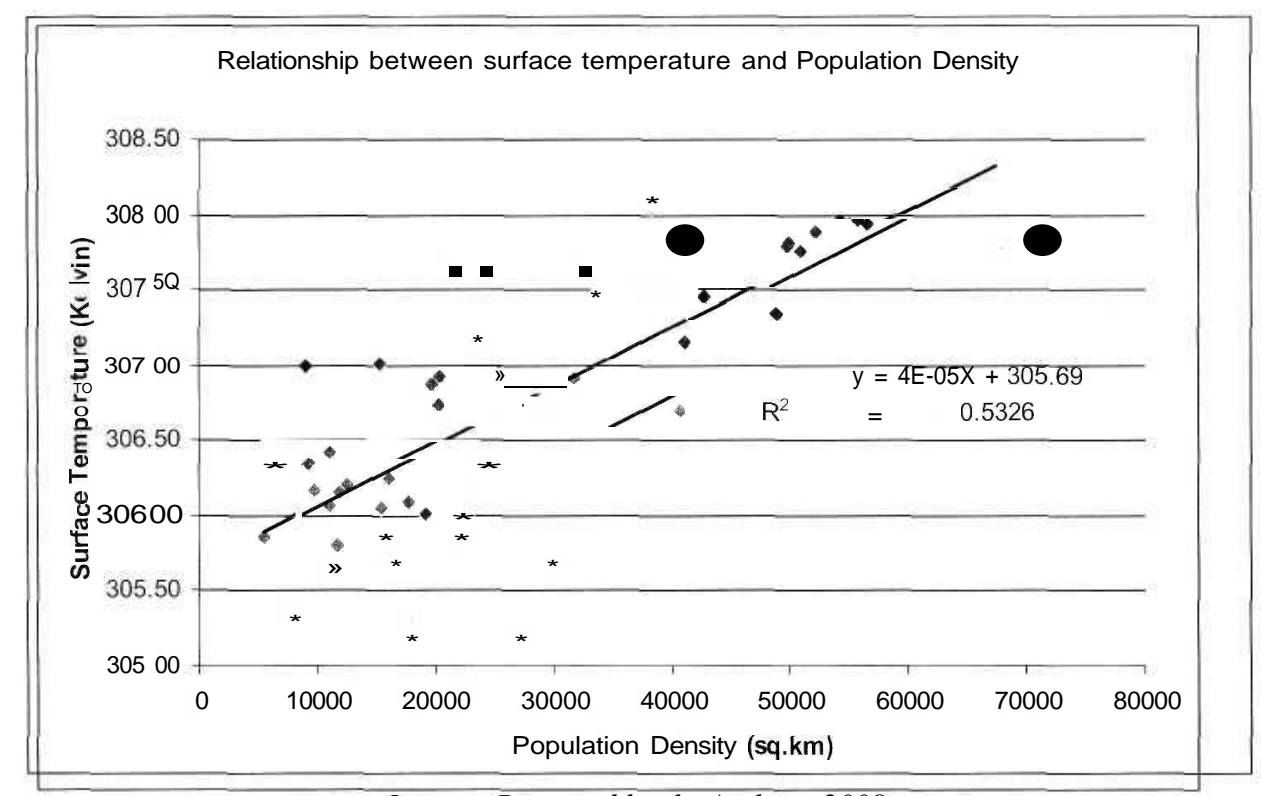

Source: Prepared by the Author - 2008

Figure 5: Surface Temperature Population - Colombo 


\subsection{Factors affecting the elevation of surface temperature in the city of Colombo}

Several socio-economic factors are contributing to the increase of temperature in urban areas. Artificial surfaces (man-made) are the most significant characteristics of urban areas such as road asphalts, building layer (year of construction, building materials), vegetation cover, open spaces (playgrounds), and land use and land cover.

\section{Surface Temperature and Population}

It is said that, generation of green house gases and the concentration of population in any area is positively correlated. A very significant relationship $(r=0.6234)$ has been identified between the distribution of population density and the surface temperature of the city of Colombo (Figure 5)

The areas showing a very high concentration of population is almost the some as the areas which show high level of surface temperature. On the other hand Municipal wards having a very low concentration of population show low concentration of surface temperature (Figure 6a, $6 \mathrm{~b}, 6 \mathrm{c}$ and $6 \mathrm{~d})$. This phenomenon pertaining to spatial distribution of population and surface temperature by Municipal wards, is clearly demonstrated by the contingency table
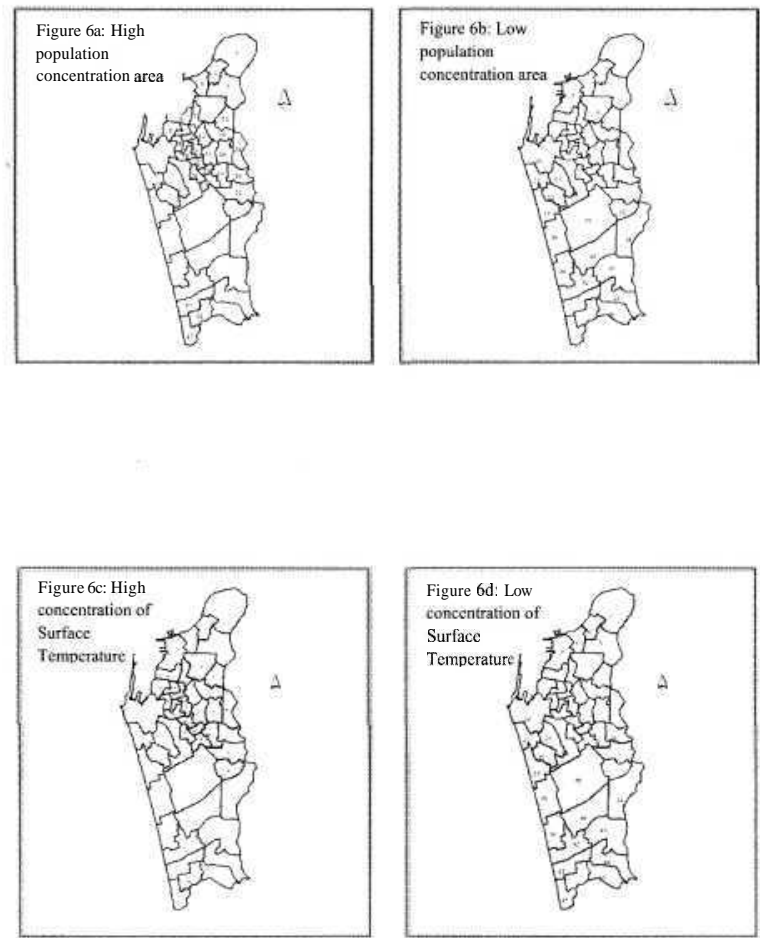

prepared based on the mean values of both variables. Out of 47 Municipal wards, 22 wards are having higher values than the mean values of population density and surface temperature and 18 wards are in the other corner. Only 9 wards have deviated from this pattern.

Due to several socio-economic chrematistics of any population, such as fuel consumption (cocking and transport), usage of CFC generating equipment (air conditioners, refrigerators Etc.), and high proportion of artificial surfaces especially in urban areas, directly affect the solar Albedo and it is reflected by the surface temperature. Though Colombo is the main commercial city of Sri Lanka, still around 20 per cent of households are using Kerosene for lighting facilities. In some wards this percentage is more than 40 per cent (Mattakkuliya 43.27\% and Fort 42.98\%). When consider the types of cocking fuel, are considered still Kerosene and Firewood show a significant importance in the city of Colombo.

\section{Surface Temperature and Floor area density}

The extent of the floor area and building area are the suitable indicators to assess the artificial surfaces of urban areas. The average percentage of building area of the city is 38.8458 (sq, km). Kochchikade North is one of the prominent outlier among the Municipal wards covering more than 95 per cent of land area by the buildings and Narahenpita shows the lowest

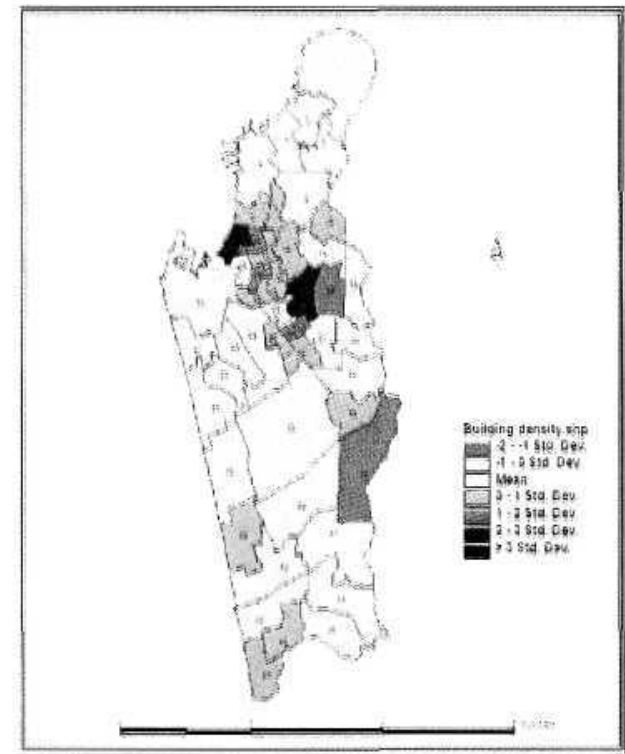

Source: prepared by author - 2008

Figure 7: Surface Temperature and Building Density 


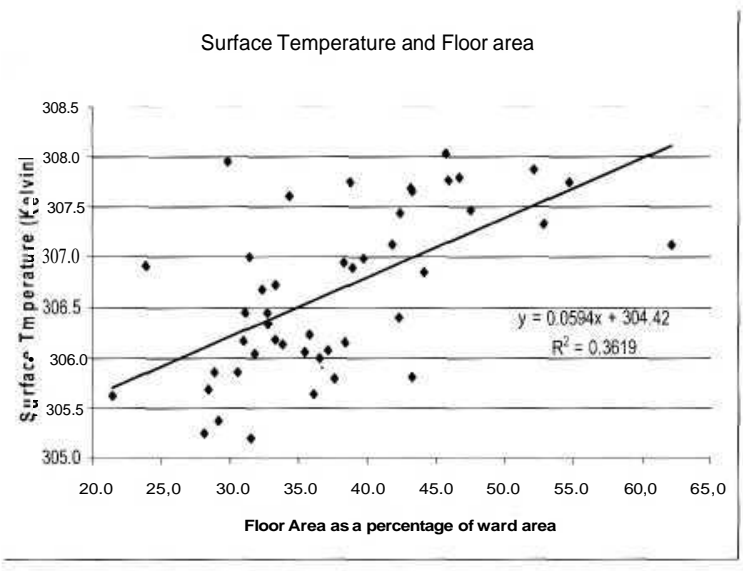

Source: prepared by author - 2008

Figure 8: Surface Temperature and Floor Area

percentage of building area. Once again the central part of the city shows high concentration of building layer. It was indicated by building density and surface temperature showing the declining trend towards the Northern and the Southern parts of the city (Figure 7). When the top ten Municipal wards having highest surface temperature and highest building percentage are compared, only 4 Municipal wards differ.

This spatial distribution of buildings of the city could be considered as an influencing factor for the surface temperature. The relationship between building layer and surface temperature is positively correlated $(r=0.4367)$ in the city of Colombo (Figure 8). The correlation coefficient demonstrates that the building area as one of the significant factors for high concentration of surface temperature in the central part of the city.

\section{Surface Temperature and Land use and Land Cover}

The surface temperature directly depends on the land use and land cover in any area. Amongst the several land use types, stores \& warehouses, harbour, manufacturing, railway and utilities are the first five land use categories which show high surface temperature in the city of Colombo. Stores and warehouses are mainly consisting of container yards located near the Colombo harbour. The area which harbour activities and container yards are located is almost similar to the area showing high surface temperature in the city. This indicates that the harbour and its related activities are some of the significant factors responsible for the surface temperature in the city. Another contributing land use

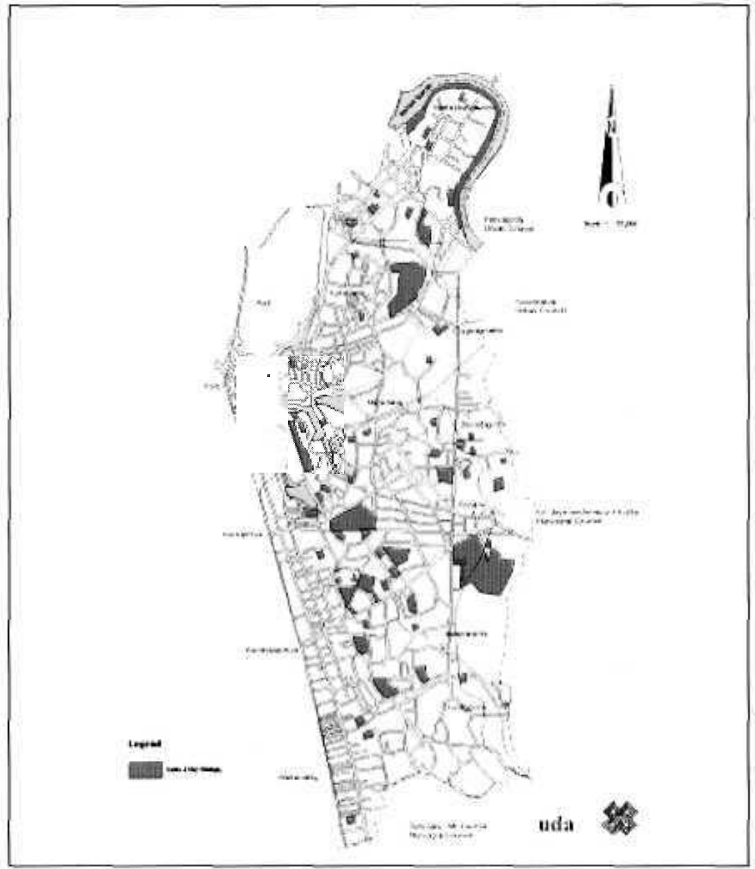

Figure 9: Forest Cover, Colombo

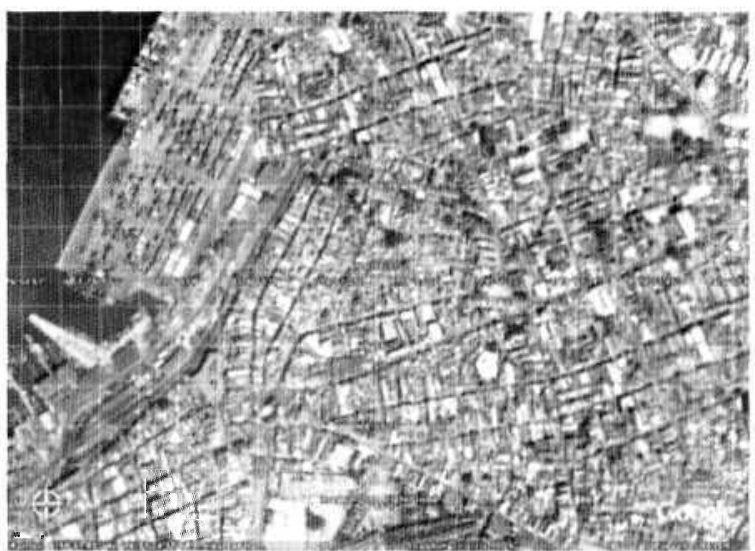

Figure 10: Colombo Harbour Area Source Google Earth

category is manufacturing sector. These activities generate heat trapping gases such as Co2, No2. On the other hand land use categories such as water bodies, Inland wetlands and beaches indicate relatively low surface temperature.

\section{Surface Temperature and Forest Cover}

Urban vegetation can directly and indirectly affect local and regional air quality by altering the urban atmosphere. The four main ways that urban trees affect air quality are: Temperature reduction and other microclimate effects, removal of air pollutants, emission of volatile organic compounds and tree maintenance emission, energy effects on buildings. 


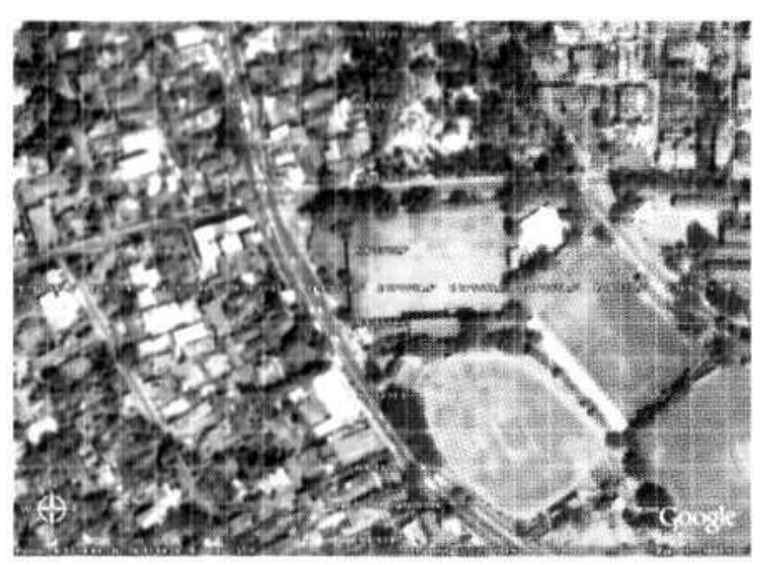

Figure 11: ThimbirigasyayaArea Source: Google Earth

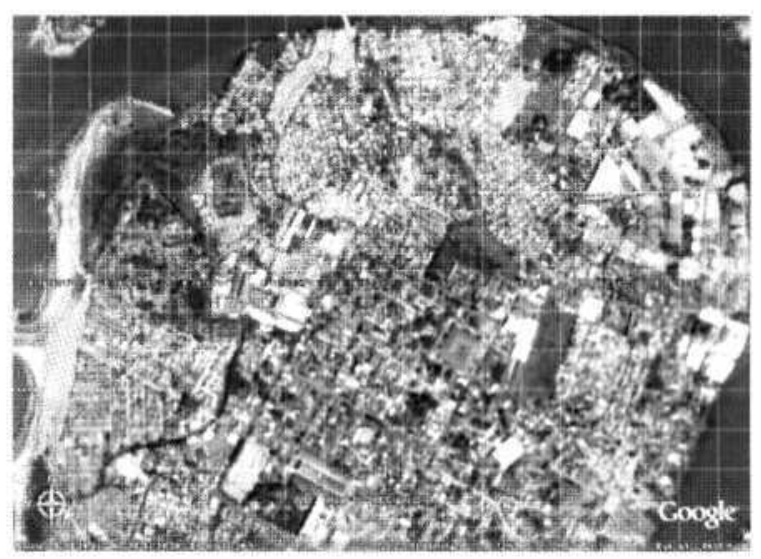

Figure 13: Mattakkuliya Source: Google Earth

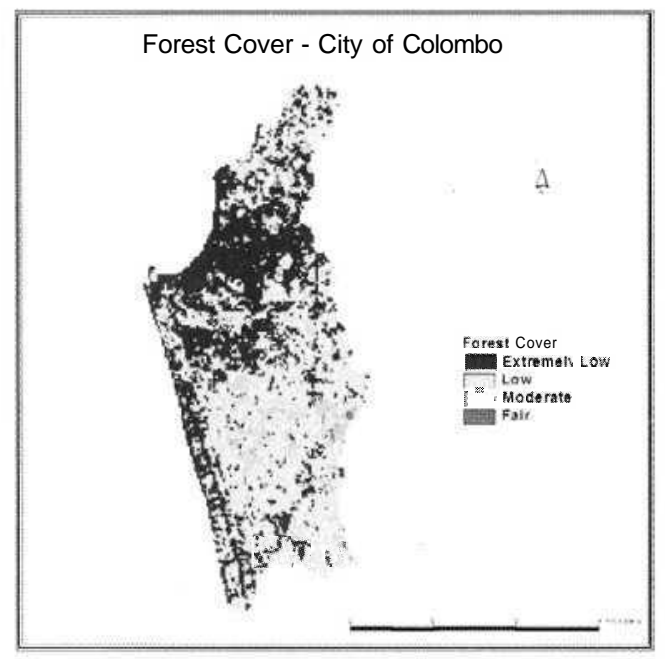

Figure 12: NDVI

Source: Prepared using Landsat Image 2008

Though, Colombo is the commercial city in Sri Lanka, still some areas with vegetation cover can be seen such as playground, urban forests and trees along the roads etc (Figure 9). The Colombo harbour and surrounded area shows very low NDVI values indicating extremely low vegetation cover.
The Google Earth gives a very clear bird eye view of this area and it can be noticed that the area has been totally covered by artificial surfaces except in a very few small scattered vegetation patches (Figure.10 - Goggle Earth).

The average surface temperature of this area is 307 Kelvin and it is almost $6 \mathrm{C}^{\circ}$ higher than the average air temperature of the city. On the other hand the Northern and the Southern parts of the city indicate relatively fair coverage of vegetation. Once again Google Earth and Figure 11 indicate the Southern part of the city has several playgrounds especially in Kuruduwatta, Thimbirigasyaya and Kirula area (Figure 11Google Earth).

These playgrounds directly influence the NDVI layer and indicate fair amount of trees in the Southern part of the city Figure 12). Although there are not many playgrounds in the Northern part of the city, NDVI indicates a fairly good distribution of trees in the Northern part of the city since there are several marshy marginal lands which NDVI reflects as fair distribution of trees (Figure 13-GoogleEarth).

The estimated surface temperature by forest types demonstrates very clear relationship between forest cover and temperature.

\section{Conclusions}

This study identifies, that the surface temperature of the city of Colombo increases day by day, due to many human activities. The surface temperature of the Colombo Metropolitan Region shows a very clear regional based distribution. It can be divided into four main regions such as,

1. Area with Very High Temperature

2. Area with High Temperature

3. Area with Moderate temperature

4. Area with Normal temperature

If we consider the City of Colombo as the main part of this study, it has significant condition on surface temperature. The city has changed into heat island concept. The average surface temperature is little bit higher than its surrounding areas. The lower value is little higher than the average air temperature of the city. It indicates the surface temperature of the city is always higher than the average air temperature. Population, Floor area density, Land use \& Land 
Cover and forest cover are the factors mostly affecting the surface temperature of the city.

The study is mostly based on satellite data (LANDSAT). So it is necessary to go for the ground verification.

\section{Acknowledgment}

The researchers gratefully acknowledge the contribution made by several scholars in developing the appropriate methodology for studying the Urban Surface Temperature using satellite remote sensing. Also we greatly appreciate the institutions which provided necessary data for this study.

\section{References}

1. Board on Atmospheric Sciences and Climate, (2006) Surface temperature reconstructions for the last 2,000 years, Washington, D.C

2. Hardy, J.T. (2003) Climate Change - Causes, Effects, and Solutions, CPL Scientific Publishing Service Ltd - UK.

3. Drunen MA, Lasage. R, Dorlands C., (2006) Climate change in Devoloping Countries, Netherland.

4. Beniston M. (2004) Climate Change and its Impacts, Switzerland

5. Streutker D. R., (2005) Satellite-measured growth of the urban heat, Rice University, Houston, Texas 